\title{
PROJETOS DE FELICIDADE NO CÁRCERE: implicações para o cuidado em saúde \\ DOI: 10.22289/2446-922X.V8N1A5
}

\author{
Beatriz Santana Caçador ${ }^{1}$ \\ Thuany Caroline Souza e Silva \\ Laylla Veridiana Castória Silva \\ Carolina da Silva Caram \\ Gian Batista Carmo \\ Antonio Aparecido Branco Júnior \\ Luíza de Alcântara Dutra \\ Bruna Pereira de Oliveira
}

\section{RESUMO}

Pesquisa realizada com o objetivo de conhecer os projetos de felicidade de uma população privada de liberdade e suas implicações para o cuidado em saúde. Para isso utilizou-se o estudo qualitativo. A coleta de dados ocorreu no período de julho de 2019 a outubro de 2020, em um presidio do interior da Zona da Mata Mineira, com 20 pessoas privadas de liberdade. Realizou-se entrevista aberta com roteiro semiestruturado, sendo submetidos à Análise de Conteúdo. Os aspectos éticos foram respeitados. Os resultados indicam que os projetos de felicidade das pessoas privadas de liberdade encontram significados, tanto em experiências pontuais do presente através da ressignificação dos modos de viver no cárcere, quanto em perspectivas futuras pela construção de pensamentos da vida após o cárcere. Também, desejam realizar projetos sociais em escolas para conscientizar jovens sobre o viver no cárcere, bem como acessar direitos fundamentais como educação e trabalho, constituir e cuidar da família e seguir uma religião. Assim, a produção subjetiva mobilizada no cárcere, produz como projeto de felicidade, participar do rompimento do ciclo perverso que historicamente aprisiona àqueles cujos direitos não são acessados na vida fora do presídio, possibilitando a construção de cuidados coerentes com a integralidade e humanização.

Palavras-chave: Prisioneiros; Saúde; Vulnerabilidade em Saúde; Assistência Centrada no Paciente.

\section{HAPPINESS PROJECTS IN PRISON: implications for health care}

\section{ABSTRACT}

Research carried out with the objective of knowing the project of happiness of a population deprived of liberty and its implications for health care. For this, the qualitative study was used. Data collection took place from July 2019 to October 2020, in a prison in the interior of Zona da Mata Mineira, with 20 people deprived of liberty. An open interview was carried out with a semi-structured script, being submitted to Content Analysis. Ethical aspects were respected. The results indicate that the happiness projects of people deprived of liberty find meanings, both in specific experiences of the

\footnotetext{
${ }^{1}$ Endereço eletrônico de contato: cacadorbeatriz2@gmail.com

Recebido em 29/10/2021. Aprovado pelo conselho editorial para publicação em 06/01/2022.
}

Rev. Psicol Saúde e Debate. Jan., 2022:8(1): 60-73. 
present through the redefinition of ways of living in prison, and in future perspectives through the construction of thoughts about life after prison. They also want to carry out social projects in schools to raise awareness of young people about living in prison, as well as accessing fundamental rights such as education and work, building and caring for the family and following a religion. Thus, the subjective production mobilized in prison, produces as a project of happiness, participating in the breaking of the perverse cycle that historically imprisons those whose rights are not accessed in life outside prison, enabling the construction of care consistent with comprehensiveness and humanization.

Keywords: Prisioners; Health; Vulnerability in Health; Pacient-Centered Care.

\section{PROYECTOS DE FELICIDAD EN PRISIÓN: implicaciones para la salud}

\section{RESUMEN}

Investigación realizada con el objetivo de conocer los proyectos de felicidad de una población privada de libertad y sus implicaciones para la salud. Para ello, se utilizó un estudio cualitativo. La recolección de datos se realizó entre julio de 2019 y octubre de 2020, en una prisión del interior de la Zona da Mata Mineira, con 20 personas privadas de libertad. Se realizó una entrevista abierta con guión semiestructurado, siendo sometida a Análisis de Contenido. Se respetaron los aspectos éticos. Los resultados indican que los proyectos de felicidad de las personas privadas de libertad encuentran significados, tanto en experiencias específicas del presente a través de la redefinición de formas de vivir en prisión, como en perspectivas de futuro a través de la construcción de pensamientos sobre la vida después de la prisión. También quieren llevar a cabo proyectos sociales en las escuelas para concienciar a los jóvenes sobre la vida en prisión, así como el acceso a derechos fundamentales como la educación y el trabajo, la construcción y cuidado de la familia y el seguimiento de una religión. Así, la producción subjetiva movilizada en la cárcel, produce como proyecto de felicidad, participando en la ruptura del ciclo perverso que históricamente aprisiona a aquellos a cuyos derechos no se accede en la vida fuera de la prisión, posibilitando la construcción de un cuidado acorde con la integralidad y la humanización.

Palabras clave: Prisioneros; Salud; Vulnerabilidad en Salud; Asistencia Centrada em el Paciente.

\section{INTRODUÇÃO}

Ao longo dos anos, as punições públicas e as violências corporais foram substituídas pela privação de liberdade, como forma de castigar e punir as sociedades. Deste modo, as prisões foram constituídas para adestrar socialmente àqueles indivíduos que eram julgados como incapazes de conviver em sociedade devido à ocorrência de alguma infração legal (Barcinski \& Cúnico, 2014).

À partir das prisões, então, o controle disciplinar e a vigilância dos corpos tornaram-se o novo dispositivo de violência, desta vez não corporal. Neste novo mecanismo de punição há um processo de sequestro das vontades e desejos daqueles que vivem no cárcere, assim, ao terem seus desejos pessoais anulados, por meio de correção e controle constantes, há também um aniquilamento dos direitos individuais e da própria vida. De tal modo, a população privada de liberdade vive um processo de deterioração de sua subjetividade ao serem invisibilizados (Barcinski \& Cúnico, 2014).

Rev. Psicol Saúde e Debate. Jan., 2022:8(1): 60-73. 
A população privada de liberdade caracteriza-se como uma população vulnerável, a qual vivencia um contexto de limitações no que concerne à garantia de direitos essenciais como acesso à saúde e às condições salubres de existência (Valim, Daibem, \& Hossne, 2018). Nessa perspectiva, é necessária a superação da lógica de negligência da população privada de liberdade, considerando que é de responsabilidade do Estado garantir os direitos humanos, especialmente daqueles que estão impossibilitados de exercê-los (Valim, Daibem, \& Hossne, 2018).

Dentre as violações de direitos das pessoas privadas de liberdade, nota-se as barreiras de acesso à saúde, expressas pelo descaso institucional e, também, por negligência de profissionais de saúde que, sob a égide da segurança e do controle, negligenciam as necessidades de saúde dessa população. Desse modo, as prisões transcendem a privação de liberdade como forma de punir pelo delito cometido e constituem-se como forma de castigo legitimado por relações de poder e obediência (Martins et al., 2014).

A população privada de liberdade sofre preconceitos, tanto dentro dos presídios, quanto aos olhares da sociedade, que, por diversas vezes, dificulta e inviabiliza a reconstrução da vida fora da prisão (OLERJ, 2018). Essa rejeição, em sua grande maioria, afeta os futuros planos, tornando os projetos de felicidades praticamente inexistentes. Neste contexto, cabe ressaltar que a privação da liberdade é por si só um fator estressor, que prejudica tanto a saúde física quanto mental dos detentos, que convivem, além disso, com condições insalubres, que agravam ainda mais a relação saúde-doença (Miranda, Rangel, \& Moura, 2016).

Neste contexto, o Sistema Único de Saúde (SUS), sob o conceito de saúde, sustenta-se na compreensão ampliada que transcende a abordagem da dimensão biológica dos sujeitos, incluindo aspectos subjetivos, culturais, espirituais e sociais em relação às condições materiais de existência (Caçador et al., 2015). Essa compreensão dos processos de saúde e adoecimento, perpassa o reconhecimento dos projetos de felicidade como participantes da construção dos processos de viver, adoecer e morrer das pessoas (Ayres, 2004).

Visto o exposto, adota-se a abordagem de Ayres (2004) a respeito da importância do reconhecimento de projetos de felicidades, o qual defende que, para que os encontros entre os trabalhadores de saúde e usuários sejam produtores de cuidado, há de se buscar a compreensão dos projetos de felicidade dos sujeitos, uma vez que norteiam o modo como as pessoas conduzem suas vidas. Desse modo, o cuidado pode reconstruir as práticas de saúde, atuando como potencial reconciliador entre as práticas assistenciais e a vida, ou seja, a possibilidade de diálogo aberto e produtivo entre a tecnologia e a ciência e a construção livre e solidária de uma vida feliz.

Nessa perspectiva, surge a inquietação do presente estudo: Quais projetos de felicidade que tecem os modos de viver das pessoas privadas de liberdade no contexto do cárcere? Para a produção de práticas de cuidado sustentadas na integralidade, precisa-se conhecer a realidade objetiva desse cotidiano e as subjetivações que nele são tecidas, as quais no cárcere, são marcadas 
pela privação não só de liberdade, mas de direitos de cidadania. Reconhecer esta subjetividade no contexto das práticas de saúde torna-se subsídio fundamental para ofertar cuidado essencialmente integral e balizado por referenciais de humanização. Assim, o presente estudo possui como objetivo conhecer os projetos de felicidade de uma população privada de liberdade e suas implicações para o cuidado em saúde.

\section{MATERIAIS E MÉTODOS}

Trata-se de um estudo qualitativo, por possuir um lugar reconhecido entre as várias possibilidades de se estudar os fenômenos que envolvem a subjetividade dos seres humanos e suas relações sociais estabelecidas em diversos ambientes. Assim, considerando que a abordagem qualitativa, enquanto exercício de pesquisa, não se apresenta como uma proposta rigidamente estruturada, permite que a imaginação e a criatividade levem os investigadores a propor trabalhos que explorem novos enfoques (Minayo, 2017).

O estudo foi realizado em um presídio do interior da Zona da Mata Mineira, com lotação de 114 pessoas, mas que durante o estudo possuía 266 detentos, entre mulheres e homens, de regime provisório, fechado, semiaberto, em prisão temporária e por débito alimentar. Os privados de liberdade estavam distribuídos em 20 celas, compostos por quatro celas femininas e 16 celas masculinas.

Participaram das entrevistas um detento de cada cela, totalizando 20 participantes, sendo quatro mulheres e 14 homens, mediante critério de conveniência. Foram convidados àqueles privados de liberdade com maior tempo de cárcere de cada cela. Os critérios de inclusão foram: idade superior a 18 anos e estar sob custódia do Estado, sentenciados para cumprimento de pena privativa de liberdade. Os critérios de exclusão foram: estar em regime semiaberto, provisórios e em prisão temporária.

Os dados foram coletados mediante entrevista aberta orientada por roteiro semiestruturado, constituído por uma primeira parte contendo questionário socioeconômico, seguido por questionamentos como "o que você sonha para sua vida", "o que te faz feliz", "quais seus planos para o futuro", dentre outros.

O estudo foi realizado entre julho de 2019 a outubro de 2020. As entrevistas foram gravadas e transcritas na íntegra, garantindo a fidedignidade dos dados, a gravação foi realizada por meio de gravador digital, com o uso liberado e acordado com o gestor do presídio em questão. Cada entrevista durou entre 40 minutos a uma hora e meia. As entrevistas foram realizadas sem a presença do agente penitenciário, em local privativo, sem qualquer inferência exterior. Dois pesquisadores previamente treinados conduziram a coleta dos dados.

Rev. Psicol Saúde e Debate. Jan., 2022:8(1): 60-73. 
Os dados foram analisados por meio da técnica de Análise de Conteúdo de Bradin (2011), a qual consiste em um conjunto de instrumentos de cunho metodológico em constante aperfeiçoamento, que se aplicam a discursos (conteúdos e continentes) extremamente diversificados por meio dos quais é possível analisar as comunicações estabelecidas entre o entrevistador e participante de forma articulada.

Foram realizadas as três etapas segundo a proposta, sendo: pré-análise, em que se organizou o material a ser analisado com o objetivo de torná-lo operacional, sistematizando as ideias iniciais; seguido pela exploração do material mediante a definição de categorias; e por último, realizou-se o tratamento dos resultados, com a condensação e o destaque das informações para análise reflexiva e crítica à luz da literatura (Bardin, 2011). Não houve utilização de aplicativos para tais análises.

O estudo respeitou os princípios éticos de pesquisa envolvendo seres humanos, em conformidade com a Resolução do Conselho Nacional de Saúde 466/2012 sobre Diretrizes e Normas Regulamentadoras de Pesquisa envolvendo Seres Humanos do Ministério da Saúde e a Resolução 510/2016 que dispõe sobre as normas aplicáveis a pesquisas em Ciências Humanas e Sociais.

Todos os direitos das pessoas em reclusão no presídio foram reservados, sendo garantido a liberdade de recusar a participação ou retirar seu consentimento no decorrer do trabalho. Os participantes que aceitaram contribuir com o estudo assinaram o Termo de Consentimento Livre e Esclarecido (TCLE). Para a preservação do anonimato dos privados de liberdade, as entrevistas foram identificadas como "entrevistado" seguido pelos números de 1 a 20 , conforme a ordem das mesmas.

\section{RESULTADOS}

Em relação ao perfil dos participantes a idade variou entre 20 a 45 anos, com maioria entre 20 e 30 anos de idade. Em relação à cor/raça, 35\% se autodeclararam negros, 30\% pardos, 30\% brancos e 5\% amarelo. No que tange à reinserção no cárcere, $60 \%$ eram reincidentes e $40 \%$ estavam cumprindo a pena pela primeira vez. Em relação à escolaridade, $40 \%$ relataram ter 0 ensino médio incompleto, $35 \%$ ensino fundamental incompleto, $10 \%$ ensino fundamental completo, $5 \%$ ensino médio completo e $10 \%$ ensino superior completo. Dentre os detentos entrevistados, $45 \%$ proferiram seguir a religião católica, outros $45 \%$ a evangélica e $10 \%$ relataram não seguir nenhuma religião.

Todos os entrevistados demostraram satisfação ao participar da pesquisa. Alguns, ao responderem algumas questões, principalmente, relacionadas à família e aos projetos de felicidade, emocionaram-se.

Rev. Psicol Saúde e Debate. Jan., 2022:8(1): 60-73. 
De acordo com o estudo, percebe-se que a noção de felicidade dos participantes no tempo presente mistura-se à noção de um projeto futuro. Em relação à essa felicidade do tempo presente, destaca-se que consideram tanto a ausência total dessa vivência subjetiva, quanto a existência de gatilhos, como o acesso a religiosidade por meio da Bíblia e também das visitas, conforme pode ser observado nos depoimentos a seguir.

Só a bíblia. (Entrevistado 8)

A hora da visita. (Entrevistado 18)

O que me faz feliz é a visita quando chega né. Só a visita. (Entrevistado 5)

O que me faz feliz é saber que a família está bem na rua, que a família e os filhos estão com saúde... isso é importante. (Entrevistado 13)

Feliz? Só a visita da minha família mesmo, semanal. (Entrevistado 17)

De acordo com a experiência vivenciada no cárcere, os privados de liberdade permitem-se experimentar ou não vivências de felicidade. Para alguns, felicidade e cárcere não possuem intercessão. Para outros, estar com a família e saber que a mesma encontra-se bem é a razão de felicidade. Ainda, há quem discorra sobre a felicidade pela vivência de uma experiência religiosa/espiritual através da leitura da Bíblia.

Dentre os projetos de felicidade traduzidos como sentido, busca e perspectiva futura e, como uma experiência de felicidade que, de algum modo, já participa da produção subjetiva do tempo presente, destaca-se o desejo de acessar direitos fundamentais como estudo, trabalho, constituir e cuidar da família, seguir uma religião e a construção da noção de sujeito, ao querer "ser alguém na vida".

Pretendo sair daqui, acabar meus estudos, fazer faculdade, e ser alguém na vida. (Entrevistado 2)

Ah, meu futuro é construir uma família, abandonar tudo que eu fiz de errado, e voltar a trabalhar, voltar a ser uma boa pessoa. (Entrevistado 4)

Pretendo dar continuidade nos meus estudos, eu tenho vontade de frequentar uma religião bacana, ter uma família, ter meus filhos, e poder ensinar eles as coisas que eu não tive. (Entrevistado 6)

Poder estudar mais um pouquinho, fazer uma faculdade algo assim, e dar uma felicidade maior pra minha família, minha esposa, pra minha filha; e regenerar, e mudar, e querer viver uma nova vida. Meu pensamento e esse! (Entrevistado 16)

É sair daqui, ser diferente, procurar um emprego, colocar os projetos que eu tenho em mente em prática, voltar pra junto da minha família que está me esperando pra isso, e tentar dar um futuro melhor pra minha filha. (Entrevistado 12)

Através dos depoimentos acima, observa-se que os participantes expressam o desejo de romper com os caminhos que os levaram até o cárcere, sinalizando a vontade de acessar estudo e trabalho, condições essas que não são realidade de todos cidadãos. O acesso ao estudo e trabalho é por eles associado ao projeto de constituir-se como "alguém na vida" e se tornarem uma "boa pessoa". Esse desejo de sair do cárcere e trabalhar revela-se como importante componente dos projetos de felicidade das pessoas privadas de liberdade.

Rev. Psicol Saúde e Debate. Jan., 2022:8(1): 60-73. 
Então meu plano é ir embora, montar uma lojinha ou alguma coisa pra mim trabalhar. (Entrevistado 1)

O que me faz feliz mesmo é só acreditar que um dia eu vou sair daqui. (Entrevistado 3)

Ah, meu projeto futuro é construir uma família, abandonar tudo que eu fiz de errado, e voltar a trabalhar. (Entrevistado 4)

É sair dessa cadeia, e lá fora conseguir um serviço e assumir minha profissão. (Entrevistado 9)

E sair daqui, ser diferente, procurar um emprego, colocar os projetos que eu tenho em mente em prática, voltar pra junto da minha família que está me esperando pra isso. (Entrevistado 12)

Ainda, compõe os projetos de felicidade o desejo de atuar na sociedade contribuindo para romper o ciclo de encarceramento de jovens, conforme relata o entrevistado 8.

O que passa mais forte na minha cabeça mesmo é um projeto social, forte nas escolas públicas, para poder estar levando e mostrando o que é a cadeia, porque mexendo na cabeça deles dessa forma, eu creio que muitos vão ter medo. Eu mesmo sou um, se eu soubesse o que era cadeia! (Entrevistado 8)

Ademais, através das entrevistas, observa-se que as noções de projeto de felicidade das pessoas privadas de liberdade encontram significados tanto em experiências pontuais do presente quanto na perspectiva futura, através da ideia que constroem e alimentam sobre como será a vida após o cárcere ou como será a liberdade.

Além disso, apreende-se que a experiência no cárcere, pode, em muitos casos, mobilizar processos de ressignificação dos modos de viver dessas pessoas e de seus projetos de felicidade, ancorados a partir do desejo expresso de romper com as escolhas que os levaram até a prisão.

Por outro lado, também evidencia-se que além de uma produção subjetiva e pessoal relacionada aos novos desejos e percepções de si, os sujeitos retratam a importância da existência de uma realidade objetiva concreta, principalmente no que tange a possibilidade de acesso aos direitos fundamentais, como estudo e trabalho.

As pessoas privadas de liberdade ao revelarem seus projetos de felicidade apreendem como um processo de reflexão sobre a própria vida - uma forma de cuidar de si - que proporciona uma reconfiguração de sua identidade, de seus valores e desejos.

No que diz respeito à saúde, em consonância ao conceito ampliado e a perspectiva da integralidade, observa-se que tais subjetivações acerca da felicidade, anteriormente citadas, como a experiência do hoje e também do projeto de amanhã, mantém-se interligadas e participam do processo de cuidado que confere sentido ao cotidiano vivenciado e contribui para que aconteça alguma produtividade, mesmo em um contexto tão dramático, violento e insalubre.

Rev. Psicol Saúde e Debate. Jan., 2022:8(1): 60-73. 


\section{DISCUSSÃO}

A população privada de liberdade apresenta-se como população vulnerável mediante à posição que ocupam na sociedade, o acesso restrito a bens e serviços e, as baixas oportunidades de estudo e trabalho, constituindo-se uma população que necessita de uma atenção à saúde específica, integral, atenta e singular (Valim, Daibem, \& Hossne, 2018).

Para tanto, é responsabilidade do Estado proteger os direitos dos cidadãos, em especial daqueles que encontram-se impossibilitados de exercê-los plenamente. Porém, ainda que existam marcos jurídicos de abrangência internacional ou regional que visam proteger os direitos das pessoas privadas de liberdade, observa-se a manutenção, de modo particular em cada local, das dificuldades que as impedem de exercer plenamente seus direitos. Para os privados de liberdade essas dificuldades assumem uma proporção maior em diversos aspectos, dentre os quais relacionam-se ao acesso à educação, trabalho e à atenção à saúde (Valim, Daibem, \& Hossne, 2018).

As pessoas privadas de liberdade, apesar da perda do direito de ir e vir, ainda possuem outros direitos fundamentais que devem sempre serem protegidos e garantidos pelo Estado, especialmente, pelo fato de estarem legalmente sob sua custódia. O direito à saúde está garantido pela Constituição Federal Brasileira de 1988, pelo SUS e por outros marcos legais (Brasil, 2016).

Segundo dados do Levantamento Nacional de Informações Penitenciárias (Infopen) (Brasil, 2016) de junho de 2016, o Brasil possui a terceira maior população carcerária do mundo, com um total de 726.712 presos e com déficit de vagas chegando a 358.663, evidenciando a superlotação que os cárceres brasileiros enfrentam. De acordo com Martins et al (2014) a população carcerária no Brasil é a maior da América Latina. Além da superlotação e frágil atenção à saúde, o sistema penitenciário brasileiro, é marcado por precárias condições de higiene e incipiente assistência jurídica, educacional e profissional, o que agrava a vulnerabilidade social dessa população, devido ao lugar marginal que ocupa na sociedade, com acesso restrito aos bens e serviços e às poucas oportunidades de vida, sendo a maioria expostos à condições desfavoráveis de vida e saúde. Portanto, essa população torna-se extremamente sujeita à adquirirem problemas físicos e mentais comparando-se à população em geral (Martins et al., 2014).

Esta realidade impõe desafios importantes para a garantia do direito à saúde, estabelecido pela Constituição Brasileira, pois todos os indivíduos apresentam necessidades básicas de saúde e possuem direito de acesso à saúde de forma equânime. A atenção equânime é um princípio da justiça social no sentido de minimizar as iniquidades que grupos vulneráveis vivência, como é o caso da população carcerária (Siqueira, Hollanda, \& Motta, 2017).

Além disso, Monteiro e Cardoso (2013) utilizaram informações do Infopen (Brasil, 2016) para analisar o quantitativo de população privada de liberdade no Brasil. No ano 2000, eram 232.755 
pessoas encarceradas e, em 2010, este número dobrou, passando para 496.251 pessoas. De toda população carcerária no Brasil em 2010, 58\% eram jovens de 18 a 29 anos (Brasil, 2016).

O Brasil experimenta, deste modo, um aumento expressivo em suas taxas de encarceramento, que vêm sendo acompanhadas de severas formas de repressão. Observa-se que há um perfil específico de população encarcerada que seleciona parte da população, pois $60 \%$ dos encarcerados no país constituem-se de pessoas negras (Monteiro \& Cardoso, 2013).

De acordo com Monteiro e Cardoso (2013) internacionalmente, é péssima a visão que se tem do sistema penitenciário brasileiro, o qual é percebido como campos de concentração para pessoas pobres, bem como depósito das escórias sociais. Assim, nem de longe cumprem algum papel de reinserção social, uma vez que $50 \%$ da população privada de liberdade no Brasil torna-se reincidente. Além disso, os encarcerados, em sua maioria, possuem baixa escolaridade e altas taxas de desemprego, os quais são depositados em massa nas prisões, a fim de promover uma perversa política de higienização social (Monteiro \& Cardoso, 2013).

De acordo com Serra e Lima (2019) essa população vivencia, antes do cárcere, uma grave condição de vulnerabilidade social, ocupando posições marginais na sociedade. Constituem-se de pessoas com acesso restrito à saúde, educação, bens e serviços, baixas oportunidades de trabalho e renda.

Nesta perspectiva, a criminalidade possui várias causas, dentre as quais destaca-se a pobreza. Além disso, a corrupção torna-se um fator mobilizador da perpetuação desta pobreza, uma vez que o dinheiro público é desviado, aumentando o número de pessoas em situações de vulnerabilidade e possibilitando a ausência de acesso às condições de cidadania (Prata, Ferrer, \& Rodrigues, 2019).

Através do perfil da população carcerária descrita na literatura e, em consonância com o perfil de participantes deste estudo, percebe-se a recorrência de um processo legitimado por parte do Estado, repressão e criminalização da pobreza. Os dados expressos pelo perfil da população carcerária sinalizam a necessidade de inclusão da desigualdade econômica e social como determinante do processo de encarceramento. Ademais, há que se introduzir neste debate o acesso à justiça por essa população já marginalizada e excluída pelo Estado (Prata, Ferrer, \& Rodrigues, 2019).

O Brasil é marcado por iniquidades em saúde de grupos vulneráveis que vivenciam um cotidiano de negação de direitos e invisibilidade (Prata, Ferrer, \& Rodrigues, 2019), emergindo nesse cenário a população carcerária. Dessa forma, o perfil da população carcerária evidencia a determinação social do seu processo saúde-doença e as condições materiais de existência marcadas pala intensa vulnerabilidade acometida.

Neste sentido, o cuidado em uma perspectiva fenomenológica, perpassa por um ampliado que vai além da assistência e tecnologia, tendo a intersubjetividade como o seu potencial 
transformador. Assim, gerar um cuidado integral em que se favoreça a humanização, a construção de vínculo com o sujeito, de forma aberta e relacional, no intuito de transformar as pessoas, seus modos de ver e viver e de promover a construção de projetos de vida autônomos e de felicidade (Carvalho et al., 2019).

O ideal das práticas no campo da saúde é superar a lógica que compreende o cuidado como cura ou mera produção de procedimentos. Ao contrário, as práticas em saúde para serem coerentes com as necessidades das pessoas precisam extrapolar a dimensão técnica e biológica, e, alcançar domínios mais profundos do ser humano, como a compreensão da subjetividade inscrita nos modos de ser de cada sujeito relacionados à sua existência (Cestari et al., 2017).

Observa-se como pressuposto que o cuidado é ontológico, isto é, próprio da condição humana. É por meio do cuidado e com o cuidado que se torna possível alcançar e concretizar os projetos de vida, os quais são construídos de acordo com as necessidades singulares de cada indivíduo, em diferentes momentos da vida, visando sua autonomia e bem-estar. Para tanto, é fundamental um cuidado ampliado e fundamentada na multi, inter e transdisciplinaridade (Cestari et al., 2017).

Ao realizar práticas de cuidado é fundamental saber qual é o projeto de felicidade, isto é, sobre qual concepção de vida bem-sucedida as pessoas orientam seus projetos singulares de existência (Ayres, 2004). Ayres (2004) faz um questionamento aos profissionais de saúde, ao indagar "qual lugar devemos ocupar na produção dos projetos de felicidade das pessoas que por nós são cuidadas?". Além disso, afirma, que constitui-se grande desafio ao profissional de saúde conhecer quais projetos de felicidade possuem as pessoas às quais oferecem o cuidado para, então, serem capazes de pensar qual a melhor maneira de participar ativamente da sua construção.

Ainda, segundo Ayres (2004), o cuidado possui como potência a capacidade de reconstruir práticas de saúde, atuando de modo a promover uma reconciliação entre as práticas assistenciais e a vida. Isso significa reconhecer que o cuidado precisa envolver uma conexão entre a ciência e as perspectivas singulares das pessoas acerca da vida que se revela feliz.

Já a felicidade, constitui-se como um conceito complexo em sua definição, pois além de ser um adjetivo difícil de descrever, apresenta-se, também, difícil de padronizar, pois entende-se que pode estar relacionada ao bem-estar objetivo, o qual é reflexo das condições de vida (moradia, segurança, saúde) e subjetivo relacionado à experiência individual e interna de cada um (Schneider, Dittrich, \& Dias, 2020).

A felicidade não depende apenas do próprio eu, mas também, das relações com o ambiente e com as pessoas, cabendo às políticas públicas contribuírem para tal, o que leva ao indivíduo a não obter controle total sobre a mesma (Schneider, Dittrich, \& Dias, 2020). Portanto, nota-se que no contexto do cárcere os privados de liberdade não conseguem obter nenhum controle, nem sobre condições materiais de existência - fortemente marcadas por insalubridade, superlotação, falta de 
higiene - nem mesmo sobre os próprios corpos e relações. Como pensar em felicidade em um contexto tão adverso do ponto de vista estrutural quanto subjetivo?

Neste sentido, a felicidade é entendida como um valor tecido mediante vivências concretas e essenciais para a vida humana (Caçador et al., 2015). Assim, constitui-se grande desafio aos profissionais de saúde construírem práticas de cuidado que englobem a dimensão da felicidade no contexto do cárcere. Isto porque, de acordo com Barcinski \& Cúnico (2014) as prisões são marcadas por violência, castigos e disciplinas que promovem um processo de mutilação da subjetividade das pessoas privadas de liberdade ao submetê-las constantemente ao poder e à força. Ademais, a retirada de direitos fundamentais constitui-se como uma suspensão da própria vida de modo que nem a própria pessoa se considera como um sujeito.

Mediante isso, o papel do Estado e da família torna-se imprescindível para o resgate da subjetividade da pessoa privada de liberdade. Isto porque, a felicidade é uma categoria complexa e multifacetada que apresenta um panorama que engloba fatores relacionados à família, às relações humanas, ao ambiente e ao espaço institucional. A relação que o indivíduo manifesta com esses fatores é fundamental para a qualidade da felicidade e ambas sustentam o aparato psicológico do indivíduo (Schneider, Dittrich, \& Dias, 2020).

Ainda, a família desempenha um papel fundamental nas relações sociais, reflexões sobre a vida e produção da subjetividade, constituindo-se como uma ligação direta entre o sujeito e o mundo externo, desse modo, tende a atuar como parceira no processo de reintegração social (Tannuss, Silva Junior, \& Oliveira, 2018).

As práticas religiosas e espirituais também apresentam seus papeis de importância na busca pela felicidade, aspectos de saúde e paz individual, por compreenderem uma dimensão subjetiva para os indivíduos (Forti, Serbena, \& Scaduto, 2018). Em 1988, a Organização Mundial de Saúde (OMS) incluiu a dimensão espiritual no conceito multidimensional de saúde, remetendo às questões como significado e sentido da vida, não se limitando a qualquer tipo específico de crença ou prática religiosa. No contexto do cárcere, a assistência religiosa é garantida pela Lei de Execução Penal que estabelece as regras necessárias para sua prestação (Lermen et al., 2015).

A espiritualidade/religiosidade possui como potência mobilizar o ser humano para o enfrentamento e superação de si e de obstáculos, contribuindo para a saúde e o bem-estar interior dos sujeitos, inclusive existem estudos com desenvolvimento de escalas para sua avaliação ao propiciarem a elaboração subjetiva e atribuição de sentido à vida pelos sujeitos (Forti, Serbena, \& Scaduto, 2018). Sendo assim, apreende-se a necessidade dos órgãos públicos e sistemas penitenciários de reconhecerem a importância das práticas religiosas no contexto do cárcere como contribuintes para melhora da saúde e ressocialização dos sujeitos. Deste modo, estabelecer redes com pastorais religiosas, proporcionar atividades que trabalhem com a dimensão subjetiva dos 
encarcerados e integração com a família, atuam como facilitadores de experiências de felicidade com potencial de ressignificar a vida no cárcere.

Ademais, importa ressaltar que como práticas de cuidado integrais, considera-se, também, a inserção de oportunidades profissionalizantes, que permitam o desenvolvimento de competências e habilidades, a fim de garantirem maiores chances de reinserção no mercado de trabalho e induzirem políticas que amenizem a ausência do Estado durante o período de vida que precedeu o encarceramento, marcado por frágil acesso à escolaridade e aos empregos formais.

Assim, a oportunidade de encontrar-se com a subjetividade das pessoas privadas de liberdade permite reforçar premissas humanizadas do cuidado, bem como resgatar a humanidade sequestrada pela estrutura de encarceramento, marcada pelo punitivismo e aniquilamento da cidadania. Além disso, enxergar o ser humano que existe atrás da infração cometida notadamente torna-se essencial para que seja possível produzir cuidados integrais e balizados por referenciais de humanização.

Espera-se que, considerando a subjetivação das pessoas privadas de liberdade do presente estudo e obtendo como prerrogativa a perspectiva de cuidado integral, haja ampliação da inserção de profissionais de saúde no contexto do cárcere, a fim de atuarem ofertando práticas de cuidado extrapolando o campo da saúde e a ênfase biologicista do cuidado.

A despeito de todo o contexto de barbárie que se traduz o sistema penitenciário no Brasil, revela-se mediante o estudo que vale a pena investir em pesquisas e construir conhecimento a respeito de como melhorar tal realidade, ampliando tal escopo e identificando limitações de políticas públicas na garantia no acesso à saúde, especialmente, de uma atenção à saúde equânime para populações em situações de vulnerabilidade como é o caso das pessoas privadas de liberdade.

O estudo possui a limitação no que concerne à coleta de dados ter sido realizada em apenas uma unidade prisional, o que restringe a generalização da análise para diferentes cenários e outros contextos prisionais.

\section{CONSIDERAÇÕES FINAIS}

Pensar em projetos de felicidade no contexto do cárcere pode soar, em um primeiro momento, como contraditório, ao considerar a realidade inóspita que traduz o cotidiano nas prisões. Entretanto, ao adotar como referencial de cuidado perspectivas de humanização e integralidade, torna-se possível perceber que tais projetos pertencem à natureza humana. Ainda que ocultados pelas vulnerabilidades e violências, os projetos de felicidade habitam, também, nas pessoas privadas de liberdade, que possuem potencial de produzir sentido e ressignificação da própria vida e das escolhas realizadas, mesmo no cárcere. 
Assim, a produção subjetiva mobilizada no cárcere produz como projetos de felicidade participar do rompimento do ciclo perverso que historicamente aprisiona àqueles cujos direitos não são acessados na vida fora do presídio, possibilitando a construção de cuidados coerentes com a integralidade e humanização.

Por esta razão, os profissionais de saúde que atuam nesse contexto devem inserir práticas de cuidado que sejam capazes de conhecer e valorizar as pessoas que existem atrás das grades que os cercam. Ademais, torna-se importante tecer articulações intersetoriais de modo a integrarem redes interdisciplinares para ofertar qualificação profissional, acesso ao estudo e o desenvolvimento de habilidades que permitam fontes de trabalho ao saírem da prisão.

Por fim, o encontro com a humanidade das pessoas privadas de liberdade promove um encontro com nossa própria humanidade e permite reconstruir referenciais preconceituosos que marcam nossa subjetividade, valores e práticas.

\section{REFERÊNCIAS}

Ayres, J. R. C. M (2004). Cuidado e reconstrução das práticas de saúde. Interface (Botucatu), vol.8, n.14, pp. 73-92. https://doi.org/10.1590/S1414-32832004000100005

Ayres, J. R. C. M. (2004). O cuidado, os modos de ser (do) humano e as práticas de saúde. Saúde soc, vol.13, n.3, pp. 16-29. https://doi.org/10.1590/S0104-12902004000300003

Barcinski, M., Cúnico, S. D. (2014). Os efeitos (in)visibilizadores do cárcere: as contradições do sistema prisional. Psicologia, Porto Alegre - RS, v. 28, n. 2, p. 63-70. https://doi.org/10.17575/rpsicol.v28i2.696

Bardin, L. (2011). Análise de conteúdo. São Paulo: Edições 70, pp. 229.

Brasil. (2014). Ministério da Saúde (MS). Política Nacional de Atenção Integral à Saúde das Pessoas Privadas de Liberdade no Sistema Prisional. Brasília: MS, Ministério da Justiça. https://bvsms.saude.gov.br/bvs/saudelegis/gm/2014/pri0001 0201 2014.html

Brasil. (2016). Ministério da Justiça. Levantamento Nacional de Informações Penitenciárias (Infopen). https://www.justica.gov.br/news/mj-divulgara-novo-relatorio-do-infopen-nesta-tercafeira/relatorio-depen-versao-web.pdf

Caçador, B. S., Brito, M. J. M., Moreira, D. A., Rezende, L. C., Vilela, G. S. (2015). Being a nurse in the family health strategy programme: challenges and possibilities. Rev Min Enferm. jul/set; 19(3): 620-626. DOI: 10.5935/1415-2762.20150047

Carvalho, P. A. L., Malhado, S. C. B., Constâncio, T. O. S., Ribeiro, I. J. S., Boery, R. N. S. O., Sena, E. L. S. (2019). Cuidado humano à luz da fenomenologia de Merleau-Ponty. Texto Contexto Enferm. 28:e20170249. https://dx.doi.org/10.1590/1980-265X-TCE-2017-0249

Cestari, V. R. F., Moreira, T. M. M., Pessoa, V. L. M. P., Florêncio, R. S., Silva, M. R. F., Torres, R. A. M. (2017). The essence of care in health vulnerability: a Heideggerian construction. Rev Bras Enferm. 70(5):1112-6. DOI: http://dx.doi.org/10.1590/0034-7167-2016-0570

Rev. Psicol Saúde e Debate. Jan., 2022:8(1): 60-73. 
Forti, S., Serbena, C. A., Scaduto, A. A. (2020). Mensuração da espiritualidade/religiosidade em saúde no Brasil: uma revisão sistemática. Ciênc. saúde coletiva, 25(4):1463-1474. https://doi.org/10.1590/1413-81232020254.21672018

Lermen, H. S., Gil, B. L., Cúnico, S. D., Jesus, L.O. (2015). Health in prison: analysis of health social policies targeting the Brazilian prison population. Physis, Rio de Janeiro, 25 [ 3 ]: 905-924 https://doi.org/10.1590/S0103-73312015000300012

Martins, E. L. C., Martins, L. G., Silveira, A. M., Melo, E, M. (2014). O contraditório direito à saúde de pessoas em privação de liberdade: o caso de uma unidade prisional de Minas Gerais. Saúde Soc. São Paulo, v. 23, n. 4, p. 1222-1234. https://doi.org/10.1590/S0104-12902014000400009.

Minayo, M. C. S. (2017). Amostragem e saturação em pesquisa qualitativa: consensos e controvérsias. Revista Pesquisa 2 Qualitativa. https://editora.sepq.org.br/index.php/rpq/article/view/82/59

Miranda, A. E., Rangel, C., Moura, R. C. (2016). Questões sobre a população prisional no Brasil: Saúde, Justiça e Direitos Humanos. UFES, Proex., v. 2, n. 1, pp. 1-192, Vitória - ES. https://proex.ufes.br/sites/proex.ufes.br/files/field/anexo/versao com isbn.pdf

Monteiro, F. M., Cardoso, G. R. (2013). A seletividade do sistema prisional brasileiro e o perfil da população carcerária: um debate oportuno. Civitas, Porto Alegre, v. 13, n. 1, p. 93-117. https://doi.org/10.15448/1984-7289.2013.1.12592

Olerj. (2018). Secretaria de Estado de Administração Penitenciária. Observatório Legislativo da Intervenção Federal na Segurança Pública do Rio de Janeiro (Olerj). Rio de Janeiro. http://olerj.camara.leg.br/

Prata, D. N., Feller, T. A., Rodrigues, W. (2019). Perfil da população carcerária e fatores ensejadores da criminalidade no sul-tocantinense. Revista de Direito da Cidade, Tocantins, v. 11, n. 4, p. 620-649. https://doi.org/10.12957/rdc.2019.41020

Schneider, A., Ditrich, M. G., Dias, M. A. H. (2020). O estudo da felicidade relacionada à política pública: uma análise bibliométrica. Interações, Campo Grande, MS, v. 21, n. 1, p. 67-79, jan./mar. https://doi.org/10.20435/inter.v21i1.1928.

Serra, A. E. G., Lima, R. C. R. O. (2019). Promoção da saúde para pessoas no regime semiaberto do sistema penitenciário: relato de experiência. Saúde debate, Rio de Janeiro, v. 43, n. 123, p. 1270-1281, out./dez. https://doi.org/10.1590/0103-1104201912322

Siqueira, S. A. V., Hollanda, E., Motta, J. I. J. (2017). Equity Promotion Policies in Health for vulnerable groups: the role of the Ministry of Health. Ciên. Saúde coletiva, 22(5):13971406. DOI: $10.1590 / 1413-81232017225.33552016$ 